\title{
I 8q loss of heterozygosity in microsatellite stable colorectal cancer is correlated with CpG island methylator phenotype-negative (CIMP-0) and inversely with CIMP-low and CIMP-high
}

\author{
Shuji Ogino*1,2,3, Takako Kawasaki ${ }^{1}$, Gregory J Kirkner ${ }^{4}$, Mutsuko Ohnishi ${ }^{1}$ \\ and Charles S Fuchs $1,3,4$
}

\begin{abstract}
Address: ${ }^{1}$ Department of Medical Oncology, Dana-Farber Cancer Institute, Boston, MA 02115, USA., ${ }^{2}$ Department of Pathology, Brigham and Women's Hospital, Boston, MA 02115, USA., ${ }^{3}$ Harvard Medical School, Boston, MA 02115, USA. and ${ }^{4}$ Department of Medicine, Brigham and Women's Hospital, Boston, MA 02115, USA.

Email: Shuji Ogino* - shuji_ogino@dfci.harvard.edu; Takako Kawasaki - takako_kawasaki@dfci.harvard.edu;

Gregory J Kirkner - gregory.kirkner@channing.harvard.edu; Mutsuko Ohnishi - mutsuko_ohnishi@dfci.harvard.edu;

Charles S Fuchs - charles_fuchs@dfci.harvard.edu

* Corresponding author
\end{abstract}

Published: 2 May 2007

BMC Cancer 2007, 7:72 doi:10.1 I86/147/-2407-7-72

This article is available from: http://www.biomedcentral.com/I47/-2407/7/72

(C) 2007 Ogino et al; licensee BioMed Central Ltd.

This is an Open Access article distributed under the terms of the Creative Commons Attribution License (http://creativecommons.org/licenses/by/2.0), which permits unrestricted use, distribution, and reproduction in any medium, provided the original work is properly cited.

\begin{abstract}
Background: The CPG island methylator phenotype (CIMP) with widespread promoter methylation is a distinct epigenetic phenotype in colorectal cancer, associated with microsatellite instability-high (MSI-high) and BRAF mutations. 18q loss of heterozygosity (LOH) commonly present in colorectal cancer with chromosomal instability $(\mathrm{CIN})$ is associated with global hypomethylation in tumor cell. A recent study has shown an inverse correlation between $\mathrm{CIN}$ and CIMP (determined by MINTs, p I6, pl4 and MLHI methylation) in colorectal cancer. However, no study has examined 18q LOH in relation to CIMP-high, CIMP-low (less extensive promoter methylation) and CIMP-0 (CIMP-negative), determined by quantitative DNA methylation analysis.
\end{abstract}

Methods: Utilizing MethyLight technology (real-time PCR), we quantified DNA methylation in 8 CIMP-specific promoters \{CACNAIG, CDKN2A (pI6), CRABPI, IGF2, MLHI, NEUROGI, RUNX3 and SOCSI\} in 758 non-MSI-high colorectal cancers obtained from two large prospective cohorts. Using four 18q microsatellite markers (DI8S55, DI8S56, DI8S67 and DI8S487) and stringent criteria for $18 \mathrm{q} \mathrm{LOH}$, we selected 374 tumors ( $236 \mathrm{LOH}$-positive tumors with $\geq 2$ markers showing $\mathrm{LOH}$; and $138 \mathrm{LOH}$-negative tumors with $\geq 3$ informative markers and no $\mathrm{LOH}$ ).

Results: CIMP-0 (0/8 methylated promoters) was significantly more common in $18 \mathrm{q} \mathrm{LOH}$-positive tumors $(59 \%=139 / 236, p=0.002)$ than $18 q \mathrm{LOH}$-negative tumors $(44 \%=6 \mathrm{I} / \mathrm{I} 38)$, while CIMPlow/high (I/8-8/8 methylated promoters) was significantly more common $(56 \%)$ in $18 \mathrm{q} \mathrm{LOH}$ negative tumors than $18 \mathrm{q} \mathrm{LOH}$-positive tumors $(4 \mathrm{l} \%)$. These relations persisted after stratification by sex, location, or the status of MSI, p 53 expression (by immunohistochemistry), or KRAS/BRAF mutation.

Conclusion: $18 \mathrm{q} \mathrm{LOH}$ is correlated positively with CIMP-0 and inversely with CIMP-low and CIMP-high. Our findings provide supporting evidence for relationship between CIMP-0 and I8q $\mathrm{LOH}$ as well as a molecular difference between CIMP- 0 and CIMP-low in colorectal cancer. 


\section{Background}

Chromosomal instability (CIN) appears to be a distinct phenotype in colorectal cancer, and tumors with CIN show frequent cytogenetic abnormalities and chromosomal gains and losses [1]. CIN is commonly assessed by $\mathrm{LOH}$ analyses of microsatellite markers, and markers in the $18 \mathrm{q}$ region appear to be generally more sensitive, compared to markers in other chromosomal regions such as $1 p, 2 p, 3 p, 5 q, 8 p$ and $17 p$ [2-5]. The presence of $18 q$ $\mathrm{LOH}$ has been proposed as a worse prognostic marker for patient survival in colorectal cancer [6-10], and appears to predict resistance to fluorouracil-based chemotherapy [11]. In particular, SMAD4 (DPC4), present in 18q21.1 and encoding a downstream signal transducer of TGF- $\beta$ (transforming growth factor- $\beta$ ), has been implicated as an important tumor suppressor lost by $18 \mathrm{q}$ deletion $[1,12]$.

Transcriptional inactivation by cytosine methylation at promoter CpG islands of tumor suppressor genes is thought to be an important mechanism in human carcinogenesis [13]. A number of tumor suppressor genes are silenced by promoter methylation in colorectal cancer [14]. Promoter CpG island methylation has been shown to occur early in colorectal carcinogenesis [15]. A subset of colorectal cancers exhibit promoter methylation in multiple genes, referred to as the CpG island methylator phenotype (CIMP) [14,16]. CIMP-high colorectal tumors appear to have a distinct clinical, pathologic and molecular profile, including associations with female sex, proximal tumor location, poor differentiation, microsatellite instability (MSI) and BRAF mutation [17-25]. In addition, we have identified CIMP-low (with less widespread promoter methylation) in colorectal cancer as a phenotype associated with male sex and KRAS mutations, different from CIMP-high and CIMP-0 (CIMP-negative) [26]. We have also shown a possible link between CIMP-low, MSI-low, MGMT methylation/silencing and KRAS mutation, supporting that CIMP-low tumors have unique molecular features different from CIMP-high and CIMP-0 tumors [27].

An association between global hypomethylation and $18 \mathrm{q}$ LOH in colorectal cancer has been shown [4]. Genomewide DNA demethylation has been correlated with chromosomal instability [28-30]. In $A p c^{\mathrm{Min} /+}$ mice, DNA hypomethylation promotes microadenoma formation through LOH at the Apc locus [31]. These studies examined genome-wide DNA methylation, but not DNA methylation in specific promoter CpG islands that is important in silencing of individual tumor suppressor genes. Recently, Goel et al. [32] has shown an inverse correlation between CIN and CIMP in colorectal cancer, using MINT1, MINT2, MINT31, p16, p14 and MLH1 methylation markers. However, no study has examined CIN in relation to CIMP-high, CIMP-low and CIMP-0, utilizing quantitative DNA methylation analysis on CIMP-specific promoters recently described by Weisenberger et al. [24].

In this study, utilizing quantitative real-time PCR (MethyLight technology) on recently described CIMP-specific promoters $[23,24]$, and colorectal cancer samples from two large prospective cohort studies, we examined relationship between $18 \mathrm{q}$ LOH and CIMP status in non-MSI$\mathrm{H}$ tumors. MethyLight assays can reproducibly distinguish high from low levels of DNA methylation, the latter of which likely have little or no biological significance [33]. We have been able to demonstrate differential relationships of CIMP-low and CIMP-0 with $18 \mathrm{q} \mathrm{LOH}$.

\section{Methods Study group}

For this study, we utilized the databases of two large prospective cohort studies; the Nurses' Health Study $(\mathrm{N}=$ 121,700 women followed since 1976) [34], and the Health Professional Follow-up Study $(\mathrm{N}=51,500$ men followed since 1986) [35]. Informed consent was obtained from all participants prior to inclusion in the cohorts. A subset of the cohort participants developed colorectal cancers during prospective follow-up. Thus, these colorectal cancers represented population-based, relatively unbiased samples (in contrast to retrospective or single-hospital-based samples). Follow-up of these cohort studies are still ongoing and outcomes data have not been available yet. Previous studies on Nurses' Health Study and Health Professionals Follow-up Study have described baseline characteristics of cohort participants and incident colorectal cancer cases, and confirmed that our colorectal cancer cases were well representative as a populationbased sample [34,35]. We collected paraffin-embedded tissue blocks from hospitals where cohort participants with colorectal cancers had undergone resections of primary tumors. We excluded cases if adequate paraffinembedded tumor tissue was not available at the time of this study. Among our cohort studies, there was no significant difference in demographic features between cases with tissue available and those without available tissue (Chan et al. in press). As a result, a total of 920 colorectal cancer cases were initially included [36]. In only seven other cases, MethyLight reactions failed (failure rate 7/927 $=0.76 \%)$. Among the 920 tumors, MSI status could be determined in 889 tumors, and 131 tumors (15\%) were MSI-H, thus leaving 758 MSI-L/MSS tumors for further analyses. For this study, we excluded MSI-H tumors because of the presence of widespread unstable microsatellites, and we selected cases only if strictly informative results of $18 \mathrm{q}$ microsatellite status were available (see below the method section for MSI and $18 \mathrm{q} \mathrm{LOH}$ ). As a result, 374 colorectal cancer cases (174 from the men's cohort and 200 from the women's cohort) were further studied. Most cases have been previously characterized for 
status of CIMP, MSI, KRAS, and BRAF [23,26,36]. However, no tumor has previously been studied for $18 \mathrm{q} \mathrm{LOH}$ status in relation to MSI and CIMP. Tissue collection and analyses were approved by the Institutional Review Boards.

\section{Genomic DNA extraction and whole genome amplification}

Tumor and normal tissue was dissected from paraffin embedded blocks and genomic DNA was extracted using QIAmp DNA Mini Kit (Qiagen, Valencia, CA USA), as previously described [37]. Normal DNA was derived from a resection margin or a random sampling of normal intestine in a resected specimen. Whole genome amplification of genomic DNA was performed by PCR using random 15-mer primers [37] for subsequent genetic analyses. Previous studies have shown that whole genome amplification does not significantly affect subsequent microsatellite analysis and gene sequencing $[37,38]$.

\section{Microsatellite instability (MSI) and I8q loss of heterozygosity (LOH)}

Methods for MSI analysis were previously described [39]. In addition to D2S123, D5S346, D17S250, BAT25 and BAT26 (the NCI panel), we used BAT40, D18S55, D18S56, D18S67 and D18S487 (i.e., a 10-marker panel); the latter four were located in 18q. "MSI-high (MSI-H)" was defined as instability in $30 \%$ or more of the markers, "MSI-low (MSI-L)" as instability in less than 30\% of the markers, and "microsatellite stability (MSS)" as no unstable marker.

For LOH analysis, we excluded MSI-H tumors because the presence of unstable microsatellites made $\mathrm{LOH}$ analysis difficult. We duplicated PCR reaction and electrophoresis in each sample for D18S55, D18S56, D18S67 and D18S487 to exclude allele dropouts of one of two alleles. $\mathrm{LOH}$ at each locus (D18S55, D18S56, D18S67 or D18S487) was defined as $40 \%$ or greater reduction of one of two allele peaks in tumor DNA relative to normal DNA [39]. In electropherograms, T1, T2, N1 and N2 were defined as peak heights of allele 1 in tumor DNA, allele 2 in tumor DNA, allele 1 in normal DNA and allele 2 in normal DNA, respectively. $\mathrm{LOH}$ at each locus was positive when $(\mathrm{T} 1 * \mathrm{~N} 2) /(\mathrm{T} 2 * \mathrm{~N} 1)$ was $\leq 6 / 10$ in two duplicated runs, or $\geq 10 / 6$ in two duplicated runs.

Overall $18 \mathrm{q}$ LOH positivity was strictly defined as the presence of at least two informative markers with $\mathrm{LOH}$, and $18 \mathrm{q}$ LOH negativity as the presence of at least three informative markers and no evidence of LOH. These stringent criteria enabled us to select biologically homogenous groups of tumors. When we used less stringent criteria in which $18 \mathrm{q}$ LOH positivity was defined as $\geq 1$ informative markers with LOH and $18 \mathrm{q}$ LOH negativity as $\geq 2$ (or $\geq 1$ ) informative markers and no evidence of $\mathrm{LOH}$, the relations between $18 \mathrm{q}$ LOH and CIMP became weaker (data not shown).

\section{Real-time PCR (MethyLight) for quantitative DNA methylation analysis}

Sodium bisulfite treatment on genomic DNA was performed as previously described [33]. Real-time PCR to measure DNA methylation (MethyLight) was performed as previously described [40,41]. Utilizing ABI 7300 (Applied Biosystems, Foster City, CA USA) for quantitative real-time PCR, we amplified 8 CIMP-specific promoters, including CACNA1G, CDKN2A (p16), CRABP1, IGF2, MLH1, NEUROG1, RUNX3 and SOCS1 [23,24]. COL2A1 (the collagen $2 \mathrm{~A} 1$ gene) was used to normalize for the amount of input bisulfite-converted DNA [33,41]. Primers and probes were previously described as follows: CACNA1G, CRABP1 and NEUROG1 [23,24],CDKN2A and COL2A1 [41]; MLH1 [33]; and IGF2, RUNX3 and SOCS1 [24]. The percentage of methylated reference (PMR, i.e., degree of methylation) at each locus was calculated by dividing the GENE:COL2A1 ratio of template amounts in a sample by the GENE:COL2A1 ratio of template amounts in SssI-treated human genomic DNA (presumably fully methylated) and multiplying this value by 100 [40]. Methylation positivity in each locus was defined as PMR > 4 (except for CRABP1 and IGF2 for which positivity was defined as PMR > 6) [23,33,41]. Precision and performance characteristics of bisulfite conversion and subsequent MethyLight assays have been previously evaluated and the assays have been validated [33].

The CpG island methylator phenotype-high (CIMP-high) was defined as the presence of $\geq 6 / 8$ methylated promoters, CIMP-low as the presence of $1 / 8$ to $5 / 8$ methylated promoters CIMP-0 as the absence $(0 / 8)$ of methylated promoters, based on the previous data that CIMP-high and CIMP-low show high BRAF and KRAS mutation rates, respectively $[26,36]$.

\section{Sequencing of KRAS and BRAF}

Methods of KRAS and BRAF sequencing have been previously described [26,37]. Pyrosequecing was performed using the PSQ96 HS System (Biotage AB and Biosystems, Uppsala, Sweden).

\section{Immunohistochemistry for p53}

Methods of tissue microarray construction [42] and p53 immunohistochemistry have previously been described [43]. p53 positivity was defined as $50 \%$ or more of tumor cells with unequivocal strong nuclear staining. All immunohistochemically-stained slides were interpreted by a pathologist (S.O.) blinded from clinical and other laboratory data. 


\section{Statistical analysis}

In statistical analysis, chi-square test (or Fisher's exact test when $\mathrm{N}<10$ in any category) was performed for categorical data, using the SAS program (version 9.1, SAS Institute, Cary, NC). All p values were two-sided, and statistical significance was set at $\mathrm{p} \leq 0.05$.

\section{Results \\ CIMP-high, CIMP-low and CIMP-O in non-MSI-H colorectal cancer}

We obtained 920 colorectal cancer specimens and quantified DNA methylation in the 8 CIMP-specific gene promoters (CACNA1G, CDKN2A, CRABP1, IGF2, MLH1, NEUROG1, RUNX3 and SOCS1) by MethyLight technology. All of the 8 loci were selected, based on screening of 195 CpG island loci throughout the human genome $[23,24]$. The use of the 8 markers as a CIMP diagnostic panel has previously been validated, and all of the 8 markers are sensitive and specific markers for CIMP-high [36]. Among the 920 tumors, MSI status could be determined in 889 tumors, and 758 tumors (85\%) were determined as MSI-L/MSS tumors for further analyses. A distribution of MSI-L/MSS tumors according to the number of methylated markers is illustrated in Figure 1, which shows associations between CIMP-high and BRAF mutations, between CIMP-low and KRAS mutations, and between CIMP-0 with wild-type BRAF/KRAS.

\section{8q LOH and MSI status}

For $18 \mathrm{q}$ LOH analysis, we analyzed four $18 \mathrm{q}$ microsatellite markers (D18S55, D18S56, D18S67 and D18S487) by duplicated PCR in MSI-L and MSS tumors. To select a biologically homogenous group of tumors (without a considerable number of misclassified tumors), we used stringent criteria for $18 \mathrm{q} \mathrm{LOH}$ positivity (i.e., the presence of at least two informative markers showing LOH). 18q LOH negativity was also strictly defined as the presence of at least three informative markers and no evidence of LOH. Among the 758 MSI-L/MSS tumors, 374 tumors were classified as either $18 \mathrm{q}$ LOH positive $(\mathrm{N}=236)$ or negative $(\mathrm{N}=138)$ by our stringent criteria. $18 \mathrm{q} \mathrm{LOH}$ was more common in MSI-L tumors $(82 \%=23 / 28, \mathrm{p}=0.05)$ than in MSS tumors $(62 \%=213 / 346)$.

\section{I8q LOH and methylation in individual CPG islands}

We examined the frequency of methylation in each marker according to the $18 \mathrm{q}$ LOH status in the MSI-L/MSS tumors (Table 1). The frequency of methylation in each marker was consistently higher in LOH-negative tumors than in LOH-positive tumors. However, no consistent relationship between $\mathrm{LOH}$ and methylation in any of the markers was present after tumors were stratified by the CIMP status (data not shown).

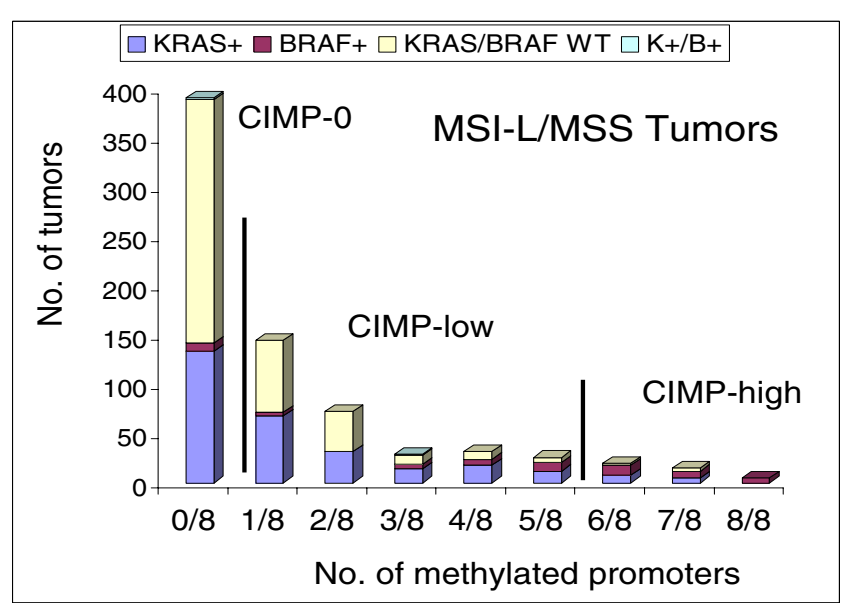

Figure I

Distribution of MSI-L/MSS colorectal cancers according to the number of methylated promoters. The $X$ and $Y$ axes indicate the number of methylated promoters and the number of tumors, respectively. Based on the KRAS and BRAF mutation rates, CIMP-high is defined as the presence of $\geq 6 / 8$ methylated promoters. Also note that CIMP-0 tumors with $0 / 8$ methylated promoters are more likely to have both wildtype KRAS and BRAF, compared to CIMP-low tumors with I/8 to 5/8 methylated promoters. Abbreviations: BRAF+, BRAFmutated KRAS wild-type; KRAS+, KRAS-mutated BRAF wildtype; $\mathrm{K}+/ \mathrm{B}+, K R A S$-mutated BRAF-mutated; KRAS/BRAF WT, both wild-type KRAS and BRAF; MSI-L, microsatellite instability-low; MSS, microsatellite stable.

\section{I8q LOH in MSI-LIMSS colorectal cancer is associated} positively with CIMP-0 and inversely with CIMP-low/high We assessed the frequency of $18 \mathrm{q}$ LOH in MSI-L/MSS tumors in relation to the number of methylated promoters (Figure 2). The frequency of $18 \mathrm{q} \mathrm{LOH}$ was highest in CIMP-0 tumors (with 0 methylated promoters), and appeared to decline as the number of methylated promoters increased. To assess relationship between $18 \mathrm{q} \mathrm{LOH}$ and CIMP, we examined the frequencies of CIMP-0 in $18 \mathrm{q}$ LOH-positive tumors and $18 \mathrm{q}$ LOH-negative tumors (Table 2). Among the $374 \mathrm{MSI}-\mathrm{L} / \mathrm{MSS}$ tumors, CIMP-0 was significantly more common in $18 \mathrm{q}$ LOH-positive tumors $(59 \%, p=0.002)$ than in $18 \mathrm{q}$ LOH-negative tumors $(44 \%)$. Even after tumors were stratified by MSI status, $18 \mathrm{q}$ LOH-positive tumors consistently showed a higher frequency of CIMP-0 than 18q LOH-negative tumors.

\section{Relationship between I8q LOH and CIMP-0 persists after various stratifications}

To examine whether the relationship between $18 \mathrm{q} \mathrm{LOH}$ and CIMP status was affected by clinical or other molecular variables, we stratified tumors by sex, tumor location, p53 status or KRAS/BRAF status, and examined the frequencies of CIMP-0 in $18 \mathrm{q} \mathrm{LOH}$ positive or negative 
Table I: Frequency of methylation in each marker according to I8q LOH status in MSI-L/MSS colorectal cancers

\begin{tabular}{|c|c|c|c|c|c|c|c|c|c|}
\hline \multirow[t]{2}{*}{ I8q LOH status } & \multirow[t]{2}{*}{ Total $\mathrm{N}$} & \multicolumn{8}{|c|}{ No. of tumors with methylation in: } \\
\hline & & CACNAIG & $C D K N 2 A(p / 6)$ & CRABPI & IGF2 & MLHI & NEUROGI & RUNX3 & SOCSI \\
\hline $\mathrm{LOH}(+)$ & 236 & $23(9.7 \%)$ & $55(23 \%)$ & $44(19 \%)$ & $28(12 \%)$ & $4(1.7 \%)$ & $44(19 \%)$ & $15(6.4 \%)$ & $15(6.4 \%)$ \\
\hline $\mathrm{LOH}(-)$ & 138 & $26(19 \%)$ & $38(28 \%)$ & $47(34 \%)$ & $30(22 \%)$ & $3(2.2 \%)$ & $41(30 \%)$ & $23(17 \%)$ & $14(10 \%)$ \\
\hline
\end{tabular}

Abbreviations: LOH, loss of heterozygosity; MSI-L, microsatellite instability-low; MSS, microsatellite stable.

tumors (Table 3). Interestingly, 18q LOH positive tumors consistently showed a higher frequency of CIMP-0 and a lower frequency of CIMP-low/high than $18 \mathrm{q} \mathrm{LOH}$ negative tumors in all of the 9 categories (male, female, right colon, left colon, etc.; 11 categories including MSI-L and MSS, $\mathrm{p}=0.0005$ ), further supporting the positive correlation between $18 \mathrm{q}$ LOH and CIMP-0.

\section{Frequency of I8q LOH in various MSI/CIMP subtypes of colorectal cancer}

A molecular classification of colorectal cancer based on MSI and CIMP status is increasingly important, because MSI and CIMP status reflect global genomic and epigenomic aberrations, respectively. We evaluated the frequency of $18 \mathrm{q} \mathrm{LOH}$ in relation to combined MSI and CIMP status (Figure 3). Either among MSI-L or MSS tumors, CIMP-0 tumors showed a higher frequency of $18 \mathrm{q}$ LOH than CIMP-low and CIMP-high tumors.

\section{Discussion}

We conducted this study to examine $18 \mathrm{q}$ loss of heterozygosity (LOH) in relation to the CpG island methylator phenotype (CIMP) in colorectal cancer. Discovering molecular correlates is important in cancer research,

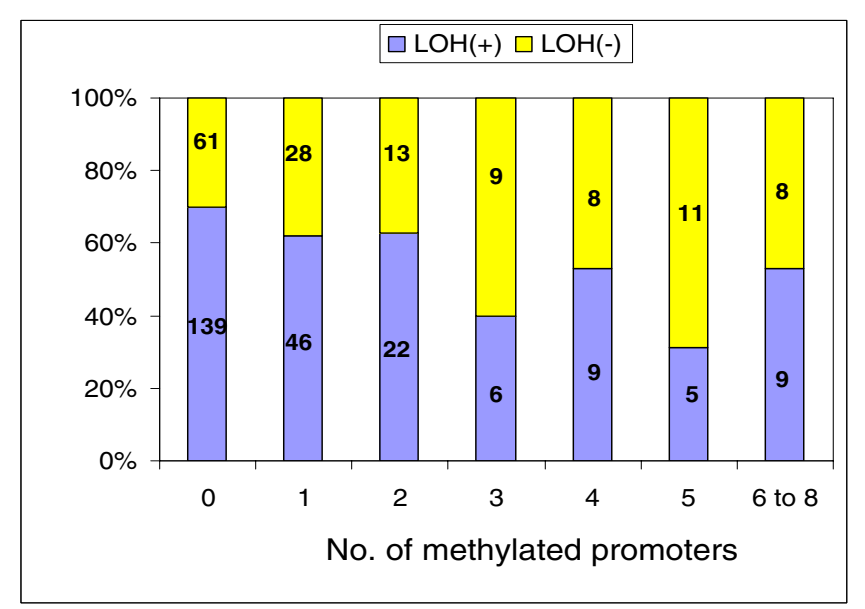

\section{Figure 2}

Frequency of $18 \mathrm{q} \mathrm{LOH}$ in MSI-L/MSS colorectal cancers, according to the number of methylated promoters. CIMP-0 tumors $(N=200)$ with 0 methylated promoters show the highest frequency of $\mathrm{I} 8 \mathrm{q} \mathrm{LOH}$. because it may: (1) provide clues to pathogenesis; (2) propose or support the existence of a new molecular subtype; (3) alert investigators to be aware of potential confounding in association studies; and (4) suggest surrogate markers in clinical or research settings. In the current study, our strict criteria for 18q LOH could select biologically more homogenous groups of samples, enabling us to identify interesting molecular correlates that might otherwise have been obscured or missed. The use of quantitative DNA methylation assays (MethyLight) on the 8 carefullyselected CIMP-specific promoters $[23,24]$ as well as population-based samples of colorectal cancer from two large prospective cohort studies $[34,35]$ has enabled us to accurately estimate the frequency of colorectal cancers with a specific molecular feature (e.g., CIMP-0).

We have demonstrated that $18 \mathrm{q} \mathrm{LOH}$ is correlated positively with CIMP-0 (with $0 / 8$ methylated promoter) and inversely with CIMP-low (1/8 to 5/8 methylated promoters). Our data are somewhat in agreement with the data by Goel et al. [32], who discovered an inverse correlation between LOH and CIMP. However, there are differences in methods and results between our study and Goel et al's study [32] that warrant discussion. Although more LOH markers were analyzed, Goel et al. [32] used non-quantitative methylation-specific PCR (MSP) assays on MINT1, MINT2, MINT31, p16 (CDKN2A), p14 (ARF), MLH1 (and additional non-CIMP related markers). The authors found only several CIMP-0 tumors (with no methylated promoter), which were too small in number to conclude a significant difference between CIMP-0 and CIMP-low. In the current study, we could demonstrate the significant difference between CIMP-low and CIMP-0 in MSI-L/MSS tumors. There might be several reasons for the discrepancies, including differences in the sample sizes, the methylation assays (MSP vs. MethyLight) and the methylation markers (MINTs vs. CIMP-high-specific markers). The use of MSP could overestimate the frequency of methylation positivity in any marker. We have shown that low-level CpG island methylation below the threshold of gene silencing should be reproducibly distinguished from high-level methylation by quantitative DNA methylation analysis [33]. The methylation markers MINT1, MINT2 and MINT31 were originally described as the markers for CIMP [16]. A recent extensive study by Weisenberger et al. [24] has shown that MINT1, MINT2 and MINT31 are not 
Table 2: Frequencies of CIMP-0 and CIMP-low/high in MSI-L/MSS colorectal cancer with or without I8q LOH

\begin{tabular}{|c|c|c|c|c|c|c|c|}
\hline & I8q LOH status & Total N & CIMP-0 $(0 / 8)^{\mathrm{a}}$ & CIMP-low/high $(1 / 8-8 / 8)^{a}$ & $P$ value & CIMP-low $(1 / 8-5 / 8)^{a}$ & CIMP-high $(6 / 8-8 / 8)^{a}$ \\
\hline All cases & & 920 & 43 I (47\%) & 489 (53\%) & & $353(38 \%)$ & $136(15 \%)$ \\
\hline \multirow[t]{2}{*}{ MSI-L/MSS } & $(+)$ & 236 & $139(59 \%)$ & $97(4 \mid \%)$ & 0.002 & $88(37 \%)$ & $9(3.8 \%)$ \\
\hline & $(-)$ & 138 & $61(44 \%)$ & 77 (56\%) & & $69(50 \%)$ & $8(5.8 \%)$ \\
\hline \multirow[t]{2}{*}{ MSI-L } & $(+)$ & 23 & 15 (65\%) & $8(35 \%)$ & & $6(26 \%)$ & $2(8.7 \%)$ \\
\hline & $(-)$ & 5 & I (20\%) & $4(80 \%)$ & & $3(60 \%)$ & I (20\%) \\
\hline \multirow[t]{2}{*}{ MSS } & $(+)$ & 213 & $124(58 \%)$ & $89(42 \%)$ & 0.01 & $82(38 \%)$ & $7(3.3 \%)$ \\
\hline & $(-)$ & 133 & $60(45 \%)$ & $73(55 \%)$ & & $66(50 \%)$ & $7(5.3 \%)$ \\
\hline
\end{tabular}

a Fraction of the number of methylated promoters.

CIMP, CpG island methylator phenotype; LOH, loss of heterozygosity; MSI-L, microsatellite instability-low; MSS, microsatellite stable.

as specific for $B R A F$ mutations as our markers, $C A C N A 1 G$, CDKN2A (p16), IGF2, MLH1, NEUROG1, RUNX3 and SOCS1. By the use of the latter markers, we could separate CIMP-high tumors (with frequent BRAF mutations) from CIMP-low tumors (with frequent KRAS mutations) (Figure 1).

Our data provide supporting evidence for a molecular difference between CIMP-low and CIMP-0 (CIMP-negative) in colorectal cancer. We have previously shown that CIMP-low tumors are associated with male sex and KRAS mutation, whereas CIMP-high tumors are associated with female sex and BRAF mutation, and CIMP-0 tumors are associated with wild-type KRAS/BRAF oncogenes and exhibits no sex predilection [26]. We have recently shown that the relationship between MSI-low and MGMT methylation/silencing is present only in CIMP-low tumors, but not in CIMP-high or CIMP-0 tumors, supporting unique molecular features of CIMP-low different from CIMP-high and CIMP-0 [27]. A significant difference in the BRAF mutation frequencies between CIMP-high and CIMP-low tumors has repeatedly been shown by other investigators [20-22,24]; however, a difference between CIMP-low and CIMP-0 has not been widely investigated. We admit that the difference between CIMP-low and CIMP-0 is not as clear-cut as that between CIMP-high and CIMP-low. Thus, additional studies are necessary to identify a panel of markers specific for CIMP-low to be clearly distinguished from CIMP-0.

The relationship between global DNA methylation level (but not specific CpG island methylation) and chromosomal aberrations has been studied. In a study using $A p c$ Min/+ mice, Yamada et al. [31] have shown that

Table 3: Frequency of CIMP in MSI-L/MSS tumors with or without $18 \mathrm{q}$ LOH after various stratifications

\begin{tabular}{|c|c|c|c|c|c|c|c|}
\hline & I8q LOH status & Total N & CIMP-0 (0/8) & CIMP-low/high (I/8 - 8/8)a & $P$ value & CIMP-low (1/8 - 5/8) & $\begin{array}{l}\text { CIMP-high } \\
(6 / 8-8 / 8)\end{array}$ \\
\hline \multirow[t]{2}{*}{ Men } & $(+)$ & 104 & $59(57 \%)$ & 45 (43\%) & 0.02 & 41 (39\%) & $4(3.8 \%)$ \\
\hline & $(-)$ & 70 & $28(40 \%)$ & $42(60 \%)$ & & $39(56 \%)$ & $3(4.3 \%)$ \\
\hline \multirow[t]{2}{*}{ Women } & $(+)$ & 132 & $80(61 \%)$ & 52 (39\%) & & 47 (36\%) & $5(3.8 \%)$ \\
\hline & $(-)$ & 68 & 33 (49\%) & 35 (5।\%) & & $30(44 \%)$ & $5(7.4 \%)$ \\
\hline \multirow[t]{2}{*}{ Right colon } & $(+)$ & 45 & $19(42 \%)$ & $26(58 \%)$ & & $23(51 \%)$ & $3(6.7 \%)$ \\
\hline & $(-)$ & 37 & $12(32 \%)$ & $25(68 \%)$ & & $21(57 \%)$ & $4(11 \%)$ \\
\hline \multirow[t]{2}{*}{ Left colon } & $(+)$ & 87 & $54(62 \%)$ & $33(38 \%)$ & & $32(36 \%)$ & $\mathrm{I}(1.9 \%)$ \\
\hline & $(-)$ & 34 & $16(47 \%)$ & $18(53 \%)$ & & 18 (53\%) & 0 \\
\hline \multirow[t]{2}{*}{$\mathrm{p} 53(+)^{\wedge}$} & $(+)$ & 122 & $73(60 \%)$ & 49 (40\%) & & 48 (39\%) & $\mathrm{I}(0.8 \%)$ \\
\hline & $(-)$ & 43 & 19 (44\%) & $24(56 \%)$ & & 22 (5।\%) & $2(4.7 \%)$ \\
\hline \multirow[t]{2}{*}{$p 53(-)^{\wedge}$} & $(+)$ & 113 & $66(58 \%)$ & 47 (42\%) & 0.03 & 39 (35\%) & $8(7.1 \%)$ \\
\hline & $(-)$ & 90 & 39 (43\%) & 51 (57\%) & & 45 (50\%) & $6(6.7 \%)$ \\
\hline \multirow[t]{2}{*}{ KRAS(-) BRAF(-) } & $(+)$ & 142 & $93(65 \%)$ & $49(35 \%)$ & & 47 (33\%) & $2(1.4 \%)$ \\
\hline & $(-)$ & 51 & 30 (59\%) & 21 (41\%) & & 21 (4I\%) & 0 \\
\hline \multirow[t]{2}{*}{ KRAS(+) BRAF(-) } & $(+)$ & 71 & 39 (55\%) & $32(45 \%)$ & & 31 (44\%) & I (I.4\%) \\
\hline & $(-)$ & 72 & 30 (42\%) & 42 (58\%) & & 39 (54\%) & $3(4.2 \%)$ \\
\hline \multirow[t]{2}{*}{ KRAS(-) BRAF(+) } & $(+)$ & 17 & $3(18 \%)$ & 14 (82\%) & & 8 (47\%) & $6(35 \%)$ \\
\hline & $(-)$ & 12 & 0 & $12(100 \%)$ & & 7 (58\%) & 5 (42\%) \\
\hline
\end{tabular}

The frequency of CIMP-0 is consistently higher in $18 \mathrm{q} L O H(+)$ tumors than in $18 q \mathrm{LOH}(-)$ tumors among the 9 different categories (men, women, right colon, etc.; I I categories including MSI-L and MSS, $p=0.0005$ ).

Footnote: a Fraction of the number of methylated promoters. ${ }^{\wedge} \mathrm{p} 53$ status was assessed by immunohistochemistry.

CIMP, CPG island methylator phenotype; LOH, loss of heterozygosity; MSI-L, microsatellite instability-low; MSS, microsatellite stable. 


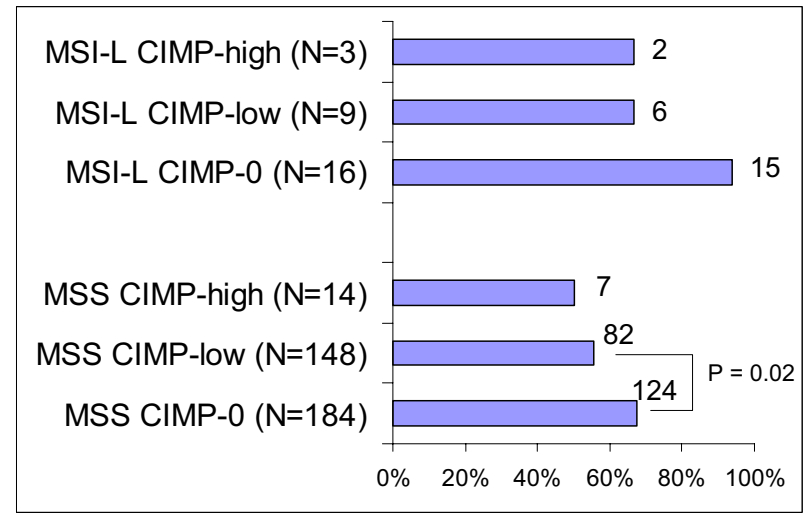

\section{Figure 3}

Frequency of I8q LOH in MSI/CIMP subtypes of colorectal cancer. CIMP-0 tumors show higher frequencies of $18 \mathrm{q} \mathrm{LOH}$ than CIMP-low and CIMP-high tumors within the MSI-L and MSS subgroups. Abbreviations: CIMP, CpG island methylator phenotype; LOH, loss of heterozygosity; MSI-L, microsatellite instability-low; MSS, microsatellite stable.

hypomorphic alleles of the Dnmt1 gene cause DNA hypomethylation in intestinal cells leading to increased microadenoma formation through LOH at the Apc locus, suggesting a pathogenetic link between DNA hypomethylation and LOH. Genome-wide DNA demethylation has been correlated with chromosomal instability and genomic copy number changes $[28,29]$. Genetic disruption of DNA methyltransferase or treatment with 5-azadeoxycytidine results in chromosomal translocations or rearrangements [30,44]. Matsuzaki et al. [4] have examined global DNA methylation levels in colorectal cancer by examining long interspersed nucleotide elements (LINE), and correlated methylation data with the status of MSI and LOH at 5q, 8p, 17p and 18q. The authors showed that the presence of $\mathrm{LOH}$ was correlated with global hypomethylation in colorectal cancer, and that the association between $18 \mathrm{q} \mathrm{LOH}$ and global hypomethylation was particularly strong compared to the associations between the other LOH markers and global hypomethylation [4]. Thus, $18 \mathrm{q}$ LOH appeared to be a good predictor for global hypomethylation. Interestingly, our current study has shown that $18 \mathrm{q}$ LOH is correlated with CIMP-0 (i.e., no methylation in the 8 CIMP-specific CpG islands). Together with the data by Matsuzaki et al. [4], there may be a possibility that a global methylation level may positively correlate with DNA hypermethylation at specific CpG islands (i.e., CIMP status). Matsuzaki et al. [4] have also shown that MSI-H tumors exhibit a higher global methylation level than MSS tumors though they have not examined MLH1 promoter methylation. These data also support the positive correlation between a global methylation level and specific promoter $\mathrm{CpG}$ island methylation, because MLH1 promoter methylation is the most common cause for sporadic MSI-H tumors and also very specific marker for CIMP-high [23].

\section{Conclusion}

We have demonstrated that $18 \mathrm{q}$ LOH in non-MSI-H colorectal cancer is correlated positively with CIMP-0, and inversely with CIMP-low and CIMP-high. Our data provide additional evidence to support a biological difference between CIMP-0 and CIMP-low in colorectal cancer. Our findings of the link between LOH and CIMP-0 indicate that potential confounding effects of CIMP status need to be considered when one examines relationship between allelic imbalance (or chromosomal instability) and patient outcomes or any other clinical or molecular variables. Additional studies will shed lights on the possible pathogenetic link between CIMP-0 and chromosomal instability in colorectal cancer.

\section{Abbreviations and HUGO Gene Nomenclature Committee (HGNC)-approved official gene symbols used}

CACNA1G, calcium channel, voltage-dependent, T type alpha-1G subunit

CDKN2A, cyclin-dependent kinase inhibitor 2A (p16, also known as INK4A)

CIMP, CpG island methylator phenotype

CIN, chromosomal instability

CRABP1, cellular retinoic acid binding protein 1

IGF2, insulin-like growth factor 2

LOH, loss of heterozygosity

MSI, microsatellite instability

MSI-H, microsatellite instability-high

MSI-L, microsatellite instability-low

MSS, microsatellite stable

NEUROG1, neurogenin 1

PMR, percentage of methylated reference (degree of DNA methylation)

RUNX3, runt-related transcription factor 3 
SOCS1, suppressor of cytokine signaling 1

\section{Competing interests}

The author(s) declare that they have no competing interests.

\section{Authors' contributions}

SO conceived the study, designed assays, analyzed and interpreted the data, and drafted the manuscript. TK designed and performed the assays, and analyzed and interpreted the data. GJK coordinated the study, and analyzed and interpreted the data. CSF coordinated the study, discussed the study design and data, and drafted the manuscript. MO provided statistical support and edited to revise the manuscript.

\section{Acknowledgements}

This work was supported by the US National Institute of Health $(\mathrm{NIH}) \mathrm{NCl}$ grants P0I CA87969 and POI CA55075, and in part by a grant from the Entertainment Industry Foundation (EIF) through the EIF National Colorectal Cancer Research Alliance (NCCRA) and by Bennett Family Fund for Targeted Therapies Research. We deeply thank the Nurses' Health Study and Health Professionals Follow-up Study cohort participants who have generously agreed to provide us with biological specimens and information through responses to questionnaires. We thank Graham Colditz, Walter Willett, and many other staff members who implemented and have maintained the cohort studies. We thank Peter Laird and Daniel Weisenberger for assistance in MethyLight assays.

\section{References}

I. Grady WM: Genomic instability and colon cancer. Cancer Metastasis Rev 2004, 23: I I-27.

2. Jass JR, Biden KG, Cummings MC, Simms LA, Walsh M, Schoch E, Meltzer SJ, Wright C, Searle J, Young J, Leggett BA: Characterisation of a subtype of colorectal cancer combining features of the suppressor and mild mutator pathways. J Clin Pathol 1999, 52:455-460.

3. Goel A, Arnold CN, Niedzwiecki D, Chang DK, Ricciardiello L, Carethers JM, Dowell JM, Wasserman L, Compton C, Mayer RJ, Bertagnolli MM, Boland CR: Characterization of sporadic colon cancer by patterns of genomic instability. Cancer Res 2003, 63:1608-|6|4.

4. Matsuzaki K, Deng G, Tanaka H, Kakar S, Miura S, Kim YS: The relationship between global methylation level, loss of heterozygosity, and microsatellite instability in sporadic colorectal cancer. Clin Cancer Res 2005, I I:8564-8569.

5. Rowan A, Halford S, Gaasenbeek M, Kemp Z, Sieber O, Volikos E, Douglas E, Fiegler H, Carter N, Talbot I, Silver A, Tomlinson I: Refining molecular analysis in the pathways of colorectal carcinogenesis. Clin Gastroenterol Hepatol 2005, 3: I I I5- I I 23.

6. Jen J, Kim H, Piantadosi S, Liu ZF, Levitt RC, Sistonen P, Kinzler KW, Vogelstein B, Hamilton SR: Allelic loss of chromosome 18q and prognosis in colorectal cancer. N Engl J Med I994, 33 I:2 I 3-22I.

7. Ogunbiyi OA, Goodfellow PJ, Herfarth K, Gagliardi G, Swanson PE, Birnbaum EH, Read TE, Fleshman JW, Kodner IJ, Moley JF: Confirmation that chromosome $18 \mathrm{q}$ allelic loss in colon cancer is a prognostic indicator. J Clin Oncol 1998, 16:427-433.

8. Zhou W, Goodman SN, Galizia G, Lieto E, Ferraraccio F, Pignatelli C, Purdie CA, Piris J, Morris R, Harrison DJ, Paty PB, Culliford A, Romans KE, Montgomery EA, Choti MA, Kinzler KW, Vogelstein B: Counting alleles to predict recurrence of early-stage colorectal cancers. Lancet 2002, 359:219-225.

9. Carethers JM, Hawn MT, Greenson JK, Hitchcock CL, Boland CR: Prognostic significance of allelic lost at chromosome I8q2 I for stage II colorectal cancer. Gastroenterology 1998, 1 14:1188-1195.
10. Watanabe T, Wu TT, Catalano PJ, Ueki T, Satriano R, Haller DG, Benson $A B$ 3rd, Hamilton SR: Molecular predictors of survival after adjuvant chemotherapy for colon cancer. $N$ Engl J Med 200I, 344: II96-I206.

II. Barratt PL, Seymour MT, Stenning SP, Georgiades I, Walker C, Birbeck K, Quirke P: DNA markers predicting benefit from adjuvant fluorouracil in patients with colon cancer: a molecular study. Lancet 2002, 360:138I-1391.

12. Alazzouzi H, Alhopuro P, Salovaara R, Sammalkorpi H, Jarvinen $H$, Mecklin JP, Hemminki A, Schwartz S Jr, Aaltonen LA, Arango D: SMAD4 as a prognostic marker in colorectal cancer. Clin Cancer Res 2005, I I:2606-26II.

13. Laird PW: Cancer epigenetics. Hum Mol Genet 2005, I4(Spec No I):R65-76.

14. Issa JP: CpG island methylator phenotype in cancer. Nat Rev Cancer 2004, 4:988-993.

15. Jass JR: Serrated adenoma of the colorectum and the DNAmethylator phenotype. Nat Clin Pract Oncol 2005, 2:398-405.

16. Toyota M, Ahuja N, Ohe-Toyota M, Herman JG, Baylin SB, Issa JP: CpG island methylator phenotype in colorectal cancer. Proc Natl Acad Sci USA 1999, 96:868I-8686.

17. Hawkins N, Norrie M, Cheong K, Mokany E, Ku SL, Meagher A, O'Connor T, Ward R: CpG island methylation in sporadic colorectal cancers and its relationship to microsatellite instability. Gastroenterology 2002, I 22:1376-1387.

18. van Rijnsoever M, Grieu F, Elsaleh H, Joseph D, lacopetta B: Characterisation of colorectal cancers showing hypermethylation at multiple CpG islands. Gut 2002, 5 I:797-802.

19. Whitehall VL, Wynter CV, Walsh MD, Simms LA, Purdie D, Pandeya N, Young J, Meltzer SJ, Leggett BA, Jass JR: Morphological and molecular heterogeneity within nonmicrosatellite instability-high colorectal cancer. Cancer Res 2002, 62:60 I I-60I4.

20. Kambara T, Simms LA, Whitehall VLJ, Spring KJ, Wynter CVA, Walsh MD, Barker MA, Arnold S, McGivern A, Matsubara N, Tanaka N, Higuchi T, Young J, Jass JR, Leggett BA: BRAF mutation is associated with DNA methylation in serrated polyps and cancers of the colorectum. Gut 2004, 53: | |37-| | 44.

21. Nagasaka T, Sasamoto H, Notohara K, Cullings HM, Takeda M, Kimura K, Kambara T, MacPhee DG, Young J, Leggett BA, Jass JR, Tanaka N, Matsubara N: Colorectal cancer with mutation in BRAF, KRAS, and wild-type with respect to both oncogenes showing different patterns of DNA methylation. J Clin Oncol 2004, 22:4584-4594.

22. Samowitz W, Albertsen H, Herrick J, Levin TR, Sweeney C, Murtaugh MA, Wolff RK, Slattery ML: Evaluation of a large, populationbased sample supports a CpG island methylator phenotype in colon cancer. Gastroenterology 2005, I 29:837-845.

23. Ogino S, Cantor M, Kawasaki T, Brahmandam M, Kirkner G, Weisenberger DJ, Campan M, Laird PW, Loda M, Fuchs CS: CpG island methylator phenotype (CIMP) of colorectal cancer is best characterised by quantitative DNA methylation analysis and prospective cohort studies. Gut 2006, 55:1000-1006.

24. Weisenberger DJ, Siegmund KD, Campan M, Young J, Long TI, Faasse MA, Kang GH, Widschwendter M, Weener D, Buchanan D, Koh H, Simms L, Barker M, Leggett B, Levine J, Kim M, French AJ, Thibodeau $S N$, Jass J, Haile R, Laird PW: CpG island methylator phenotype underlies sporadic microsatellite instability and is tightly associated with BRAF mutation in colorectal cancer. Nat Genet 2006, 38:787-793.

25. Domingo E, Espin E, Armengol M, Oliveira C, Pinto M, Duval A, Brennetot C, Seruca R, Hamelin R, Yamamoto H, Schwartz S Jr: Activated BRAF targets proximal colon tumors with mismatch repair deficiency and MLHI inactivation. Genes Chromosomes Cancer 2004, 39: I38-142.

26. Ogino S, Kawasaki T, Kirkner GJ, Loda M, Fuchs CS: CpG island methylator phenotype-low (CIMP-low) in colorectal cancer: possible associations with male sex and KRAS mutations. J Mol Diagn 2006, 8:582-588.

27. Ogino S, kawasaki T, Kirkner GJ, Suemoto Y, Meyerhardt JA, Fuchs CS: Molecular correlates with MGMT promoter methylation and silencing support $C_{p G}$ island methylator phenotype-low (CIMP-low) in colorectal cancer. Gut 2007 in press. (published online first on March 5, 2007).

28. Rodriguez J, Frigola J, Vendrell E, Risques RA, Fraga MF, Morales C, Moreno V, Esteller M, Capella G, Ribas M, Peinado MA: Chromosomal Instability Correlates with Genome-wide DNA 
Demethylation in Human Primary Colorectal Cancers. Cancer Res 2006, 66:8462-9468.

29. Suzuki K, Suzuki I, Leodolter A, Alonso S, Horiuchi S, Yamashita K, Perucho M: Global DNA demethylation in gastrointestinal cancer is age dependent and precedes genomic damage. Cancer Cell 2006, 9:199-207.

30. Karpf AR, Matsui S: Genetic disruption of cytosine DNA methyltransferase enzymes induces chromosomal instability in human cancer cells. Cancer Res 2005, 65:8635-8639.

31. Yamada Y, Jackson-Grusby L, Linhart H, Meissner A, Eden A, Lin H, Jaenisch R: Opposing effects of DNA hypomethylation on intestinal and liver carcinogenesis. Proc Natl Acad Sci USA 2005, 1 02: | 3580- I 3585

32. Goel A, Nagasaka T, Arnold CN, Inoue T, Hamilton C, Niedzwiecki D, Compton C, Mayer RJ, Goldberg R, Bertagnolli MM, Boland CR: The CpG Island Methylator Phenotype and Chromosomal Instability Are Inversely Correlated in Sporadic Colorectal Cancer. Gastroenterology 2007, I32:127-138.

33. Ogino S, kawasaki T, Brahmandam M, Cantor M, Kirkner GJ, Spiegelman D, Makrigiorgos GM, Weisenberger DJ, Laird PW, Loda M, Fuchs CS: Precision and performance characteristics of bisulfite conversion and real-time PCR (MethyLight) for quantitative DNA methylation analysis. J Mol Diagn 2006, 8:209-2 I7.

34. Colditz GA, Hankinson SE: The Nurses' Health Study: lifestyle and health among women. Nat Rev Cancer 2005, 5:388-396.

35. Giovannucci E, Liu Y, Rimm EB, Hollis BW, Fuchs CS, Stampfer M], Willett WC: Prospective Study of Predictors of Vitamin D Status and Cancer Incidence and Mortality in Men. J Natl Cancer Inst 2006, 98:45I-459.

36. Ogino S, kawasaki T, Kirkner GJ, Kraft P, Loda M, Fuchs CS: Evaluation of markers for $\mathrm{CpG}$ island methylator phenotype (CIMP) in colorectal cancer using a large population-based sample. J Mol Diagn 2007 in press.

37. Ogino S, Kawasaki T, Brahmandam M, Yan L, Cantor M, Namgyal C Mino-Kenudson M, Lauwers GY, Loda M, Fuchs CS: Sensitive sequencing method for KRAS mutation detection by Pyrosequencing. J Mol Diagn 2005, 7:4|3-42I.

38. Dietmaier W, Hartmann A, Wallinger S, Heinmoller E, Kerner T, Endl E, Jauch KW, Hofstadter F, Ruschoff J: Multiple mutation analyses in single tumor cells with improved whole genome amplification. Am J Pathol 1999, I 54:83-95.

39. Ogino S, Brahmandam M, Cantor M, Namgyal C, Kawasaki T, Kirkner G, Meyerhardt JA, Loda M, Fuchs CS: Distinct molecular features of colorectal carcinoma with signet ring cell component and colorectal carcinoma with mucinous component. Mod Pathol 2006, 19:59-68.

40. Eads CA, Danenberg KD, Kawakami K, Saltz LB, Blake C, Shibata D, Danenberg PV, Laird PW: MethyLight: a high-throughput assay to measure DNA methylation. Nucleic Acids Res 2000, 28:E32.

41. Widschwendter M, Siegmund KD, Muller HM, Fiegl H, Marth C, Muller-Holzner E, Jones PA, Laird PW: Association of breast cancer DNA methylation profiles with hormone receptor status and response to tamoxifen. Cancer Res 2004, 64:3807-38I3.

42. Ogino S, Brahmandam M, kawasaki T, Kirkner GJ, Loda M, Fuchs CS: Combined analysis of COX-2 and p53 expressions reveals synergistic inverse correlations with microsatellite instability and CpG island methylator phenotype in colorectal cancer. Neoplasia 2006, 8:458-464.

43. Ogino S, kawasaki T, Kirkner G], Yamaji T, Loda M, Fuchs CS: Loss of nuclear p27 (CDKNIB/KIPI) in colorectal cancer is correlated with microsatellite instability and CIMP. Mod Patho 2007, 20:15-22.

44. Ji W, Hernandez R, Zhang XY, Qu GZ, Frady A, Varela M, Ehrlich M: DNA demethylation and pericentromeric rearrangements of chromosome I. Mutat Res 1997, 379:33-4I.

\section{Pre-publication history}

The pre-publication history for this paper can be accessed here:

http://www.biomedcentral.com/1471-2407/7/72/prepub 